ASTHMA

\title{
Early allergen exposure, skin prick responses, and atopic wheeze at age 5 in English children: a cohort study
}

\author{
P Cullinan, S J MacNeill, J M Harris, S Moffat, C White, P Mills, A J Newman Taylor
}

Thorax 2004;59:855-861. doi: 10.1136/thx.2003.019877

See end of article for authors' affiliations

...................

Correspondence to:

Dr P Cullinan, Department

of Occupational and

Environmental Medicine,

Imperial College School of

Medicine at the National

Heart and Lung Institute,

Manresa Road, London

SW3 6LR, UK;

p.cullinan@ic.ac.uk

Received 5December 2003 Accepted 12 May 2004

\begin{abstract}
Background: For many years it has been assumed that the risk of childhood respiratory allergies is related to allergen exposures in early life. There are, however, few prospective data in support. We aimed to examine this relationship in a representative cohort of children born in Ashford, Kent (UK).

Methods: 625 children (94\% of those eligible) were followed from birth to the age of 5.5 years at which time 552 underwent skin prick testing to extracts of house dust mite and cat fur allergens. Maternal reports of wheeze in the last year were collected by interview. These outcomes were related to individual domestic concentrations of Der $p 1$ and Fel $d$ I allergens estimated from dust collection at the age of 8 weeks.

Results: $10 \%$ of children were sensitised to house dust mite or cat at age 5.5 years; $7 \%$ had atopic wheeze. No significant relationships between allergen exposure and either sensitisation or wheeze were found but, on examination, the exposure-response relationships for both allergens and for each outcome rose steeply at low levels of exposure and were attenuated at high levels of exposure. These patterns were modified by paternal atopy and by birth order.

Conclusions: There are no linear relationships between early allergen exposure and the induction of childhood respiratory allergy; rather, the risks of IgE sensitisation and asthma rise at very low levels of exposure and are attenuated thereafter. These patterns are influenced by parental atopy and birth order. These findings suggest important gene-environment interactions in the development of atopy and asthma and imply that reductions in domestic allergen exposure alone are unlikely to have a major impact in decreasing the incidence of these diseases in childhood.
\end{abstract}

F or at least 20 years, but with varying conviction, it has been held that the risk of childhood respiratory allergies is correlated with the intensity of allergen exposure in early life. If true, this would imply that lowering the levels of allergen, particularly in the home, would reduce the incidence of these diseases. Most of the information in support of this claim is derived from cross sectional surveys or case referent studies, each subject to the potential for major bias. ${ }^{1}$ However, a small number of prospective studies have been published. The first of these, describing a small cohort of high risk newborn babies in south west England, reported a weak association between infant exposure to mite allergen and both specific sensitisation and current wheezing at age $11 .^{2}$ A much larger and more recent study, again including children selected on the basis of parental allergy but with relatively low exposures to house dust mite and cat allergens, reported significant associations between early exposure to both dust mite and cat allergens and the development of specific IgE antibodies, but not the development of wheeze. ${ }^{3}$ In primary school children the acquisition of a positive skin prick test to dust mite is associated with antigen levels in their mattresses, a relationship strongly modified by atopy. ${ }^{5}$ More recently, but on the basis of cross sectional data, it has been suggested that high current exposures to $\mathrm{Fel} d \mathrm{l}$ (but not Der $p$ l) induce tolerance towards the development of specific sensitisation and asthma. ${ }^{6}$

Given the continuing uncertainty over this important issue, we devised a prospective study of normal children specifically to test the null hypothesis that early allergen exposure does not influence the development of either specific IgE sensitisation or of associated asthma.

\section{METHODS}

Over 18 months and starting in late 1993, we approached (without exception) every woman who presented for antenatal care to three general practices in Ashford, Kent (UK). Of 710 whom we invited to take part in a longitudinal study of childhood asthma, 658 (93\%) agreed and subsequently 625 women gave birth to 642 babies. At recruitment we carried out skin prick tests on the women and on the fathers of their children, using extracts of three common aeroallergens supplied by Allergopharma (Hamburg, Germany): Dermataphagoides pteronyssinus, cat fur, and mixed grass pollens. We also asked mothers and fathers to report personal histories of asthma, hayfever, or childhood eczema.

When the children were aged 8 weeks we measured the concentrations of $\mathrm{Der} p \mathrm{l}$ and $\mathrm{Fel} d \mathrm{l}$ allergens in the dust from their living room floor. We used standard techniques for both dust collection and allergen assay which we have described in full elsewhere. ${ }^{7}$ In this way, exposure measurements were made for 624 (97\%) of the cohort children.

Annually for the next 6 years we interviewed the children's mothers, almost always in person, using a standardised questionnaire that enquired into their child's wheezing symptoms over the past year. We also collected information on other potentially important factors such as sibship, sibling allergy, cigarette smoking in the home, and occupation from which we derived where possible an index of socioeconomic status. ${ }^{7}$ The results presented here are those from interviews held when the child was aged 5.5 years. At that age we also performed skin prick tests on each child using the same antigen extracts described above. These procedures were done without knowledge of the children's allergen exposures. Questionnaires were completed for 604 (94\%) children of whom 552 (86\% of the original cohort) also had skin tests.

There were no differences between those children who underwent skin prick tests and those who did not with respect to maternal allergy or either maternal or paternal atopy. However, fathers of children who had a skin prick test were more likely to report a history of allergic disease $(41 \% \mathrm{v}$ 


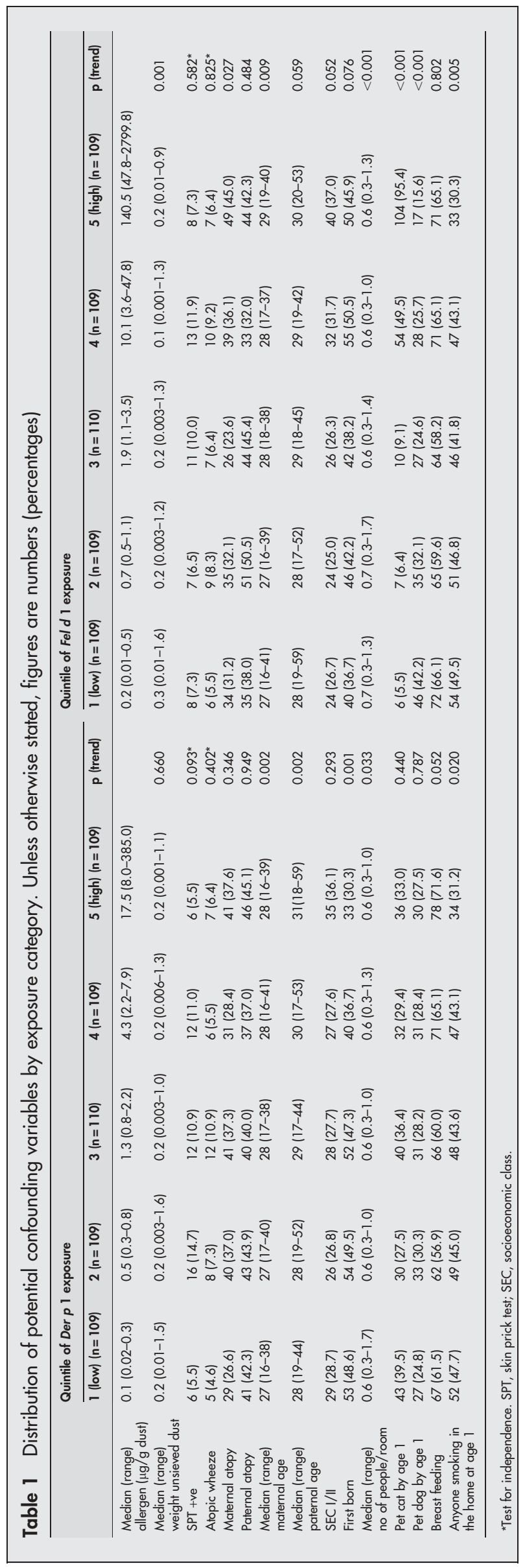

26\%; $\mathrm{p}=0.01)$. Domestic concentrations of both $\operatorname{Der} p \mathrm{l}$ and $\mathrm{Fel} d \mathrm{l}$ were similar for those children who underwent a skin prick test $(\mathrm{n}=552)$ and those who did not.

Ethical approval for the study was granted by the ethics committees of the National Heart and Lung Institute and the Kent and Medway Strategic Health Authority. Written informed consent was obtained for all participants.

\section{Analysis of data}

This analysis is confined to the 552 children for whom we collected outcome information at the age of $51 / 2$ years. Because their fathers were unemployed, in the Armed Forces, or absent, we could not estimate socioeconomic status for 54 children; for 51 children we did not have a measure of paternal atopy. For the exposure-response analysis we constructed categories of exposure defined by equal quintiles of allergen concentration (table 1). As in our original protocol we considered three outcomes: a positive skin test to dust mite, a positive test to cat allergens, and any reported wheeze in the past year in association with atopy. We categorised parents and children as atopic if they had a positive skin test to one or more allergen extracts. For adults a $3 \mathrm{~mm}$ mean weal diameter was considered to be positive but for children we used a $2 \mathrm{~mm}$ diameter. Children were described as "wheezing" if they were reported to have had at least one episode in the year prior to interview. Parents were termed "allergic" if they reported a personal history of either asthma, hayfever or childhood eczema.

The statistical significance of the distributions of categorised variables was assessed using the $\chi^{2}$ test (for trend as appropriate). For continuous variables, differences between outcome groups were assessed using the Wilcoxon rank sum test and trends across levels of exposure were assessed using Cuzick's non-parametric test for trend. The correlation between the different exposure concentrations was determined by the Pearson coefficient of the log transformed data. For multivariate analysis of the categorised exposure measurements we used a forward fitting stepwise logistic regression model in which allergen exposure was included regardless of statistical significance. Analyses were performed using SAS (SAS Institute Inc, Cary, NC, USA), Stata (Stata Corporation, TX, USA) and Splus (Lucent Technologies, WA, USA) software.

\section{RESULTS}

\section{Allergen exposures}

Domestic allergen concentrations were available for 547 of the 552 children who had skin prick tests. The geometric mean Der $p$ l concentration was 1.4 (95\% CI 1.2 to 1.6$) \mu \mathrm{g} / \mathrm{g}$ sieved dust (range 0.02-385.0). For Fel $d \mathrm{l}$ the equivalent figures were 3.4 (95\% CI 2.7 to 4.2 ) $\mu \mathrm{g} / \mathrm{g}$ dust (range $0.01-$ 2799.8). There was no correlation between the concentrations of the different allergens within the same home $(\rho=-0.01$, $\mathrm{p}=0.76$ ). Table $\mathrm{l}$ shows the distributions of some potentially confounding variables by quintile of allergen exposure. Neither parental atopy, parental allergic disease, nor sibling allergic disease (data not shown) were related to dust concentrations of $\operatorname{Der} p$ 1; mothers living in homes with high $\mathrm{Fel} \mathrm{d}$ l levels were more likely to be atopic but there were no associations with maternal asthma or paternal or sibling allergy (data not shown). Children whose homes had higher Der $p$ l concentrations were more likely to have older siblings and to live in less crowded conditions, although the variation in the latter was small. Children with high $\mathrm{Fel} d \mathrm{l}$ exposures were less likely to have an older sibling but they too tended to live in less crowded homes. There was a very strong relationship between cat ownership and quintile of $\mathrm{Fel} d \mathrm{l}$ concentration, and a similarly strong but inverse relationship 


\begin{tabular}{lll} 
Table 2 & Frequencies of outcomes at age 5.5 years \\
\hline & $\mathbf{n}(\%)$ & $\mathbf{n}(\%)$ atopic \\
\hline $\begin{array}{l}\text { Positive skin prick tests } \\
\text { Dust mite }\end{array}$ & $53(9.6)$ & \\
Cat fur & $47(8.5)$ & \\
Grass pollens & $49(8.9)$ & \\
Any allergen (atopic) & $92(16.7)$ & \\
Wheeze in past 12 months & & \\
None & $456(82.6)$ & $53(11.6)$ \\
Occasional (1-6 episodes) & $85(15.4)$ & $31(36.5)$ \\
Frequent (>6 episodes) & $11(2.0)$ & $8(72.7)$ \\
\hline
\end{tabular}

with dog ownership. Cigarette smoking was less common in homes with high concentrations of each allergen.

\section{Outcomes}

Ninety two children (17\%) were atopic at the age of 5.5 years; there were almost equal frequencies of positive skin tests to each of the individual allergens (table 2). Most of the children had not wheezed in the past year; they were far less often atopic than wheezing children, particularly those with frequent wheeze. Thirty nine children were both wheezing and atopic at the age of 5.5 years. Almost all of these $(n=34$, $87 \%$ ) had had a diagnosis of asthma made by a doctor compared with $20 \%$ of the remaining children.

Table 3 shows the distributions of potential confounding variables for the three outcomes. Each outcome was more common among children with atopic parents (significantly so for atopic fathers) and among children who were first born. Children from homes where nobody smoked were less likely to have had atopic wheeze in the previous year. Examination of other potentially confounding variables (data not shown) indicated that, although the differences were small, children from less crowded homes were less likely to have any of the three outcomes $(p=0.02$ in each case). The mothers of children with a positive skin test to dust mite were a little older (mean age 29.1 years) than those of children who were not sensitised in this way (27.6 years, $\mathrm{p}=0.05)$. There was a similar pattern for children with atopic wheeze (29.2 years $v$ 27.6 years, $\mathrm{p}=0.06$ ).

\section{Exposure-response relationships}

The proportions of children who had positive skin prick tests to specific allergens or atopic wheeze are shown by quintile of exposure in figs 1 and 2. The exposure-response relationships for each allergen were neither linear nor monotonic, but displayed an increase in risk at low levels of exposure followed by a flattening or, in some cases, a reduction of risk at higher exposures. The results of logistic modelling are shown in tables 4 and 5. Crude and adjusted odds ratios estimated for each variable, including quintile of exposure, were very similar with the exception of atopic wheeze and $\mathrm{Fel} d \mathrm{l}$ exposure, suggesting little confounding by the variables in the models. The intensity of allergen exposure did not contribute significantly to the fit of any of the models but, in each case, the patterns of odds ratios-as with the unadjusted frequencies reported above-showed a steep increase at low levels of exposure with attenuated risks at high levels of exposure. Other variables retained in the final models differed but parental allergy (variously expressed) and being the first born child were consistently included.

Figures 1 and 2 also show the proportions of sensitised or wheezing children after stratification by paternal atopy and separately by "first born" family position. The exposureresponse patterns described above appeared to be confined to children who were first born or whose fathers were atopic;

Table 3 Distributions of potential confounding variables by outcome. Unless otherwise stated, figures are numbers (percentages)

\begin{tabular}{|c|c|c|c|c|c|c|c|}
\hline & $\mathrm{N}$ & $\begin{array}{l}\text { Positive skin test } \\
\text { dust mite }\end{array}$ & $p$ value & $\begin{array}{l}\text { Positive skin test cat } \\
\text { fur }\end{array}$ & t p value & Atopic wheeze & p value \\
\hline \multicolumn{8}{|c|}{ Maternal atopy } \\
\hline No & 367 & $31(8.5)$ & \multirow[t]{2}{*}{0.188} & $29(7.9)$ & \multirow[t]{2}{*}{0.462} & $22(6.0)$ & \multirow[t]{2}{*}{0.161} \\
\hline Yes & 184 & $22(12.0)$ & & $18(9.8)$ & & $17(9.2)$ & \\
\hline \multicolumn{8}{|c|}{ Paternal atopy } \\
\hline No & 294 & $18(6.1)$ & \multirow[t]{2}{*}{0.001} & $20(6.8)$ & \multirow[t]{2}{*}{0.060} & $13(4.4)$ & \multirow[t]{2}{*}{0.003} \\
\hline Yes & 207 & 32 (15.5) & & $24(11.7)$ & & $24(11.6)$ & \\
\hline \multicolumn{8}{|c|}{ Maternal asthma } \\
\hline No & 477 & $42(8.8)$ & \multirow[t]{2}{*}{0.109} & $37(7.8)$ & \multirow[t]{2}{*}{0.109} & $29(6.1)$ & \multirow[t]{2}{*}{0.023} \\
\hline Yes & 75 & 11 (14.7) & & $10(13.3)$ & & 10 (13.3) & \\
\hline \multicolumn{8}{|c|}{ Paternal asthma } \\
\hline No & 472 & $43(9.1)$ & \multirow{2}{*}{0.268} & $39(8.3)$ & \multirow{2}{*}{0.490} & $28(5.9)$ & \multirow{2}{*}{0.007} \\
\hline Yes & 76 & 10 (13.2) & & $8(10.7)$ & & 11 (14.5) & \\
\hline \multicolumn{8}{|c|}{ Socioeconomic class* } \\
\hline I/II & 146 & $17(11.6)$ & \multirow[t]{2}{*}{0.384} & $19(13.0)$ & \multirow[t]{2}{*}{0.018} & $13(8.9)$ & \multirow[t]{2}{*}{0.188} \\
\hline III-V & 352 & $32(9.1)$ & & $23(6.6)$ & & $20(5.7)$ & \\
\hline \multicolumn{8}{|c|}{ First born } \\
\hline No & 318 & $23(7.2)$ & \multirow[t]{2}{*}{0.028} & $20(6.3)$ & \multirow[t]{2}{*}{0.028} & $15(4.7)$ & \multirow[t]{2}{*}{0.012} \\
\hline Yes & 234 & $30(12.8)$ & & $27(11.6)$ & & $24(10.3)$ & \\
\hline \multicolumn{8}{|c|}{ Pet cat by age 1} \\
\hline No & 370 & $39(10.5)$ & \multirow[t]{2}{*}{0.286} & $34(9.2)$ & \multirow[t]{2}{*}{0.413} & $25(6.8)$ & \multirow[t]{2}{*}{0.687} \\
\hline Yes & 182 & $14(7.7)$ & & $13(7.1)$ & & $14(7.7)$ & \\
\hline \multicolumn{8}{|c|}{ Pet dog by age 1} \\
\hline No & 398 & $40(10.1)$ & 0.565 & $36(9.1)$ & 0.468 & $29(7.3)$ & 0.744 \\
\hline Yes & 154 & $13(8.4)$ & & 11 (7.1) & & $10(6.5)$ & \\
\hline Breast & & & & & & & \\
\hline No & 205 & $14(6.8)$ & 0.089 & $16(7.8)$ & 0.639 & $10(4.9)$ & 0.123 \\
\hline Yes & 347 & $39(11.2)$ & & $31(9.0)$ & & $29(8.4)$ & \\
\hline Anyone & & & & & & & \\
\hline home o & & & & & & & \\
\hline No & 317 & $25(7.9)$ & 0.112 & $25(7.9)$ & 0.547 & $16(5.1)$ & 0.032 \\
\hline Yes & 235 & 28 (11.9) & & $22(9.4)$ & & $23(9.8)$ & \\
\hline
\end{tabular}



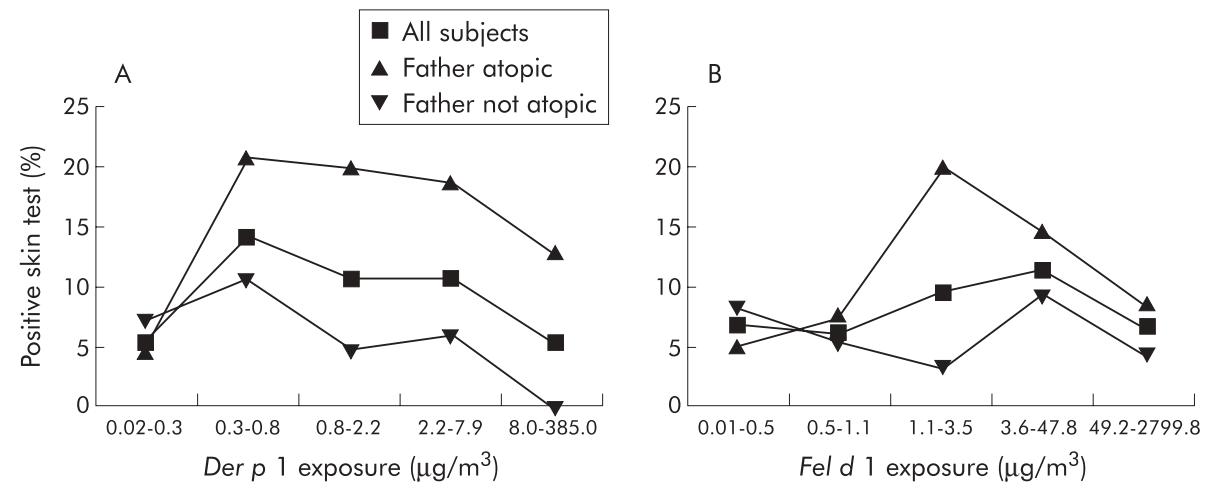

C

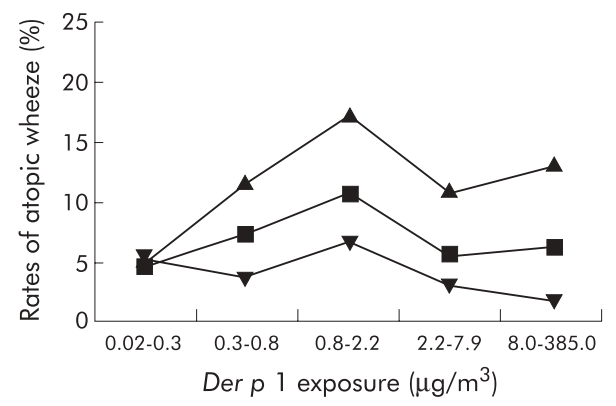

D

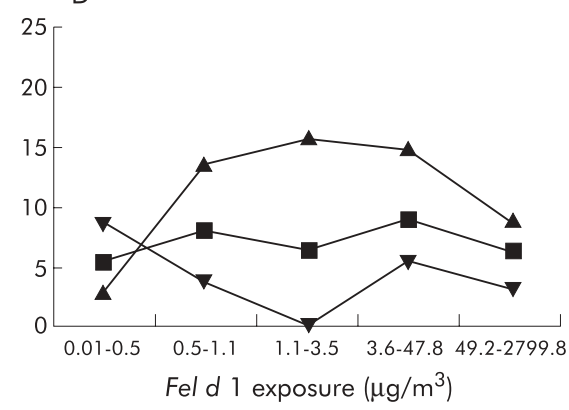

Figure 1 Rates of (A) dust mite sensitisation by quintile of Der $p 1$ exposure, (B) cat sensitisation by quintile of Fel $d 1$ exposure, (C) atopic wheeze by quintile of Der $p 1$ exposure and (D) atopic wheeze by quintile of Fel $d 1$ exposure, all stratified by paternal atopy.

for other children the relationships were essentially flat. After adjustment, the interactions between Der $p$ l exposure and paternal atopy were statistically significant for both sensitisation and atopic wheeze $(p=0.032$ and $p=0.031$, respectively). Similarly, there was a significant interaction between Der $p$ l exposure and first born position for the outcome "atopic wheeze" $(p=0.001)$. Other interactions between exposure and paternal atopy or first born position were not statistically significant (all p>0.05) after adjustment.

\section{DISCUSSION}

These findings derive from a prospectively studied group of otherwise unremarkable children living in south east England. They indicate that there are no monotonic relationships between early domestic allergen exposures and subsequent IgE sensitisation or atopic asthma at the age of 5 years. Indeed, within the strictures of conventional levels of statistical significance, our results suggest that there are no associations at all and are thus compatible with our original null hypothesis.

However, an over-reliance on measures of significance may cloak important associations ${ }^{8}$ and we believe that our findings deserve further scrutiny. On inspection, they reveal non-linear relationships with a rapid rise in risk at low levels of exposure and an attenuation of risk at higher exposures. The relationships were importantly dependent on birth order and on a marker of inherited susceptibility. Remarkably, the patterns for the two allergens were very similar, despite their uncorrelated exposure levels. With a cross sectional design, similar findings have been reported for Fel $d 1^{6}$ and high dose attenuation of exposure-response curves is not uncommon in occupational settings, although there too the explanations are debated. ${ }^{9}{ }^{10}$

We do not think the findings can be explained by losses to follow up. We failed to collect full outcome data from $14 \%$ of eligible children, in most cases because they were living too far away for skin testing. These children did not, however, differ in any important respects from those we did see. Nor do we believe that we are witnessing a behavioural ("healthy home") effect whereby families with a stronger tendency to the development of allergic disease systematically maintain a relatively low allergen environment. This seems an improbable explanation in this population. None of our measures of family risk, including parental and sibling allergy or asthma, was consistently correlated with allergen exposure. Furthermore, our exposure-response estimates were generally unchanged by adjustment for any of these indices. Very few families in this population reported having taken any sustained active measures to reduce allergen levels in the home.

For the most part we relied on categorical exposure estimates and, in the absence of prior biologically meaningful levels of allergen exposure, we elected to use percentiles (quintiles presented here). We recognise that this approach can obscure important differences within categories, especially where these (like our highest quintile) incorporate a wide range of exposures. We found no important differences, however, between analyses using several different percentile widths or varying bands of allergen exposure, or through modelling exposure continuously using a generalised additive method (data available on request). Exposure estimates in studies such as this are based on a single, albeit individual, measurement from one site and at one time point and are almost certainly open to misclassification. Fortunately, studies of domestic allergen concentrations in similar settings have demonstrated a fair degree of reliability, ${ }^{11-13}$ and our measurements displayed appropriate internal validity (for example, Fel $d$ l $v$ cat ownership). Although we collected annual reports of respiratory symptoms for this cohort, we chose to wait until the children were sufficiently old for us reasonably to distinguish "asthma" from other earlier childhood wheezing, the prognostic significance of which is unclear. The incidence of specific sensitisation and of "atopic asthma" in this cohort is rather lower than many would have 

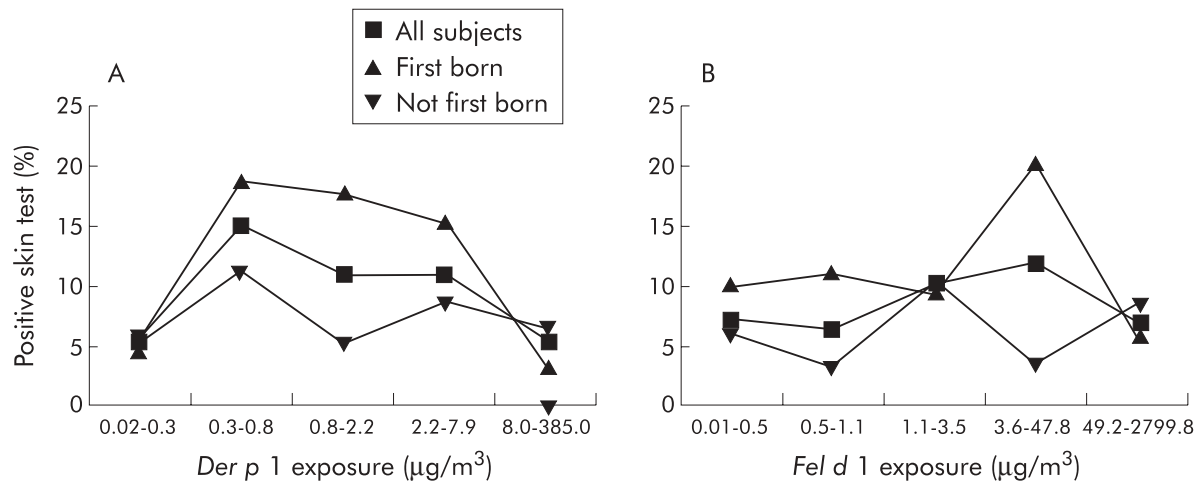

C
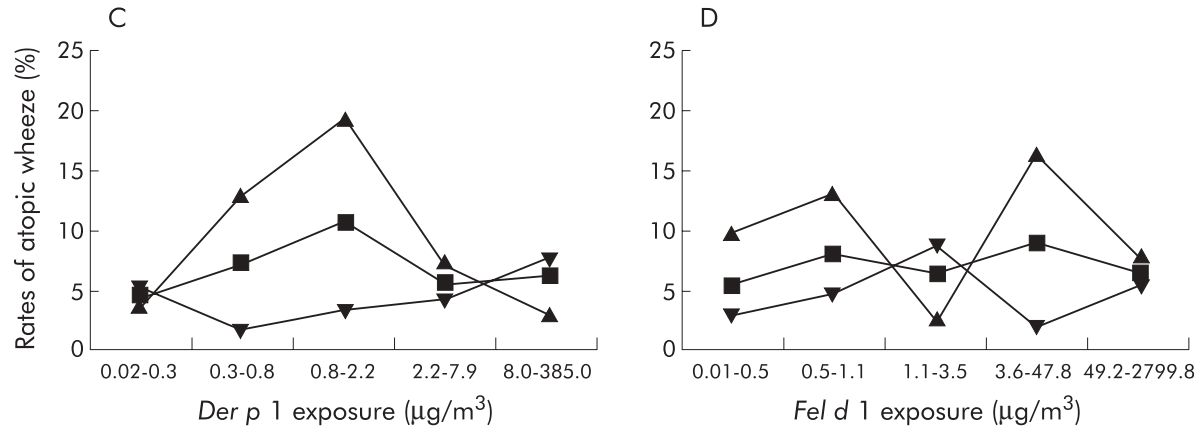

Figure 2 Rates of (A) dust mite sensitisation by quintile of Der $p 1$ exposure (B) cat sensitisation by quintile of Fel d 1 exposure, (C) atopic wheeze by quintile of Der $p 1$ exposure and (D) atopic wheeze by quintile of Fel $d 1$ exposure, all stratified by birth order.

expected. There seems little room for doubt over our measurement of specific sensitisation; in 374 children who provided a blood sample at the age of 4 there was close agreement $(>92 \%)$ between the results of the skin tests and levels of serum-specific IgE antibodies (data available). The close relationships between wheeze frequency and atopy suggest that our symptom classification was appropriately specific; and we were able clearly to reproduce other associations (such as those between sensitisation and sibship) reported from much larger cohorts. Nonetheless, it is probable that the asthmatic phenotype is not yet expressed in a proportion of the cohort children. Only if delayed presentation were correlated with early allergen exposure (and in this case the highest exposures) would this have seriously distorted our findings. We are currently re-examining the children who are now aged 8 years.

Table 4 Determinants of positive skin tests to dust mite and to cat fur derived from logistic regression

\begin{tabular}{|c|c|c|c|c|c|}
\hline & n (\%) & $\begin{array}{l}\text { Crude OR* } \\
(95 \% \mathrm{CI})\end{array}$ & n (\%) & $\begin{array}{l}\text { Adjusted OR* } \\
(95 \% \mathrm{Cl})\end{array}$ & p value ${ }^{* *}$ \\
\hline \multicolumn{6}{|l|}{ Dust mite sensitisation } \\
\hline First born & $234(42.4)$ & 1.89 (1.06 to 3.34$)$ & $215(43.4)$ & $2.06(1.05$ to 4.06$)$ & 0.035 \\
\hline Maternal age & 551 & 1.07 (1.01 to 1.13 ) & 496 & $1.10(1.02$ to 1.18$)$ & 0.008 \\
\hline Breast feeding & $347(62.9)$ & $1.73(0.91$ to 3.27$)$ & $319(64.3)$ & $1.88(0.90$ to 3.95$)$ & 0.084 \\
\hline Anyone smoking at age 1 & $235(42.6)$ & $1.58(0.90$ to 2.79$)$ & $198(39.9)$ & $2.67(1.39$ to 5.12$)$ & 0.003 \\
\hline Paternal atopy & $207(41.3)$ & $2.80(1.53$ to 5.15$)$ & $207(41.7)$ & $3.20(1.68$ to 6.09$)$ & $<0.001$ \\
\hline \multicolumn{6}{|c|}{ Quintile of Der $p 1$ (low) exposure } \\
\hline 1 & $109(20.0)$ & 1.00 & $97(19.6)$ & 1.00 & 0.147 \\
\hline 2 & $109(20.0)$ & 2.95 (1.11 to 7.86$)$ & $98(19.8)$ & $2.92(1.04$ to 8.17$)$ & \\
\hline 3 & $110(20.2)$ & $2.10(0.76$ to 5.82$)$ & $100(20.2)$ & $1.98(0.68$ to 5.80$)$ & \\
\hline 4 & $109(20.0)$ & $2.12(0.77$ to 5.88$)$ & $100(20.2)$ & $2.09(0.71$ to 6.17$)$ & \\
\hline 5 & $109(20.0)$ & $1.00(0.31$ to 3.20$)$ & $101(20.4)$ & $1.02(0.30$ to 3.44$)$ & \\
\hline \multicolumn{6}{|l|}{ Cat fur sensitisation } \\
\hline First born & $233(42.3)$ & 1.95 (1.07 to 3.58$)$ & $204(44.4)$ & $2.55(1.27$ to 5.14$)$ & 0.007 \\
\hline Social class (I/II) & $146(29.4)$ & $2.13(1.12$ to 4.05$)$ & $140(30.5)$ & $2.14(1.08$ to 4.25$)$ & 0.032 \\
\hline Sex & $295(53.5)$ & 1.95 (1.03 to 3.70$)$ & $246(53.6)$ & $2.15(1.04$ to 4.45$)$ & 0.034 \\
\hline Paternal atopy & $206(41.2)$ & 1.81 (0.97 to 3.37$)$ & $195(42.5)$ & $1.91(0.96$ to 3.80$)$ & 0.064 \\
\hline \multicolumn{6}{|c|}{ Quintile of Fel $d 1$ (low) exposure } \\
\hline 1 & $109(20.0)$ & 1.00 & $78(17.0)$ & 1.00 & 0.592 \\
\hline 2 & $109(19.8)$ & $0.88(0.31$ to 2.50$)$ & $90(19.6)$ & $0.93(0.27$ to 3.27$)$ & \\
\hline 3 & $110(20.2)$ & $1.40(0.54$ to 3.63$)$ & 91 (19.8) & $1.70(0.54$ to 5.33$)$ & \\
\hline 4 & $109(20.0)$ & $1.71(0.68$ to 4.31$)$ & $97(21.1)$ & $1.77(0.57$ to 5.50$)$ & \\
\hline 5 & $109(20.0)$ & $1.00(0.36$ to 2.77$)$ & $103(22.4)$ & $1.00(0.30$ to 3.35$)$ & \\
\hline
\end{tabular}


Table 5 Determinants of atopic wheeze by allergen exposure derived from logistic regression

\begin{tabular}{|c|c|c|c|c|c|}
\hline & n $(\%)$ & $\begin{array}{l}\text { Crude OR* } \\
(95 \% \mathrm{Cl})\end{array}$ & n $(\%)$ & $\begin{array}{l}\text { Adjusted OR* } \\
(95 \% \mathrm{Cl})\end{array}$ & p value ${ }^{* *}$ \\
\hline \multicolumn{6}{|l|}{ Der $p 1$ exposure } \\
\hline Paternal asthma & $76(13.9)$ & $2.68(1.27$ to 5.65$)$ & 68 (13.7) & $2.50(0.98$ to 6.40$)$ & 0.060 \\
\hline Maternal asthma & 75 (13.6) & $2.38(1.11$ to 5.10$)$ & 69 (13.9) & 2.41 (1.01 to 5.74$)$ & 0.057 \\
\hline First born & $234(42.4)$ & 2.31 (1.18 to 4.51$)$ & $214(43.2)$ & 3.00 (1.16 to 7.72$)$ & 0.020 \\
\hline Maternal age & 551 & $1.07(1.00$ to 1.15$)$ & 495 & $1.12(1.03$ to 1.22$)$ & 0.007 \\
\hline \multicolumn{6}{|c|}{ Crowding (persons per room) } \\
\hline $0.25-0.50$ & $100(18.1)$ & 1.00 & $89(18.0)$ & 1.00 & 0.060 \\
\hline $0.51-0.60$ & $132(23.9)$ & $0.87(0.38$ to 1.97$)$ & $121(24.4)$ & $0.95(0.35$ to 2.60$)$ & \\
\hline $0.61-0.70$ & $151(27.4)$ & $0.20(0.06$ to 0.64$)$ & $135(27.3)$ & $0.23(0.06$ to 0.88$)$ & \\
\hline $0.71-1.66$ & $169(30.6)$ & $0.41(0.17$ to 1.02$)$ & $150(30.3)$ & $0.79(0.23$ to 2.68$)$ & \\
\hline Any smoking at age 1 & $235(42.6)$ & $2.04(1.05$ to 3.96$)$ & $197(39.8)$ & $3.67(1.67$ to 8.04$)$ & $<0.001$ \\
\hline Paternal atopy & $207(41.3)$ & $2.83(1.41$ to 5.71$)$ & $207(41.8)$ & $2.88(1.26$ to 6.13$)$ & 0.011 \\
\hline \multicolumn{6}{|c|}{ Quintile of Der $p 1$ (low) exposure } \\
\hline 1 & $109(20.0)$ & 1.00 & $97(19.6)$ & 1.00 & 0.546 \\
\hline 2 & $109(20.0)$ & $1.65(0.52$ to 5.21$)$ & $97(19.6)$ & $1.35(0.37$ to 4.88$)$ & \\
\hline 3 & $110(20.2)$ & $2.55(0.87$ to 7.49$)$ & $100(20.2)$ & $2.44(0.75$ to 7.92$)$ & \\
\hline 4 & $109(20.0)$ & $1.21(0.36$ to 4.09$)$ & $100(20.2)$ & $1.16(0.30$ to 4.48$)$ & \\
\hline 5 & $109(20.0)$ & $1.43(0.44$ to 4.64$)$ & $101(20.4)$ & $1.71(0.47$ to 6.23$)$ & \\
\hline \multicolumn{6}{|l|}{ Fel $d 1$ exposure } \\
\hline Paternal asthma & 76 (13.9) & $2.68(1.27$ to 5.65$)$ & 68 (13.7) & 2.62 (1.05 to 6.57$)$ & 0.045 \\
\hline First born & $234(42.4)$ & 2.31 (1.18 to 4.51$)$ & $215(43.4)$ & $3.05(1.21$ to 7.69$)$ & 0.015 \\
\hline Maternal age & 551 & $1.07(1.00$ to 1.15$)$ & 495 & $1.11(1.02$ to 1.20$)$ & 0.012 \\
\hline Maternal asthma & $75(13.6)$ & $2.38(1.11$ to 5.10$)$ & 69 (13.9) & $2.43(1.03$ to 5.76$)$ & 0.052 \\
\hline \multicolumn{6}{|c|}{ Crowding (persons per room) } \\
\hline $0.25-0.50$ & $100(18.1)$ & 1.00 & $89(18.0)$ & 1.00 & 0.026 \\
\hline $0.51-0.60$ & $132(23.9)$ & $0.87(0.38$ to 1.97$)$ & $122(24.7)$ & $1.05(0.40$ to 2.77$)$ & \\
\hline $0.61-0.70$ & $151(27.4)$ & $0.20(0.06$ to 0.64$)$ & $135(27.3)$ & $0.21(0.05$ to 0.78$)$ & \\
\hline $0.71-1.66$ & $169(30.6)$ & $0.41(0.17$ to 1.02$)$ & $149(30.1)$ & $0.74(0.22$ to 2.49$)$ & \\
\hline Anyone smoking at age 1 & $235(42.6)$ & $2.04(1.05$ to 3.96$)$ & $198(40.0)$ & $3.53(1.61$ to 7.72$)$ & 0.001 \\
\hline Paternal atopy & $207(41.3)$ & $2.83(1.41$ to 5.71$)$ & $207(41.8)$ & $2.64(1.18$ to 5.92$)$ & 0.017 \\
\hline \multicolumn{6}{|l|}{ Quintile of Fel $d 1$ exposure } \\
\hline 1 & $109(20.0)$ & 1.00 & $91(18.4)$ & 1.00 & 0.688 \\
\hline 2 & $109(20.0)$ & $1.55(0.53$ to 4.50$)$ & $101(20.4)$ & $1.14(0.36$ to 3.65$)$ & \\
\hline 3 & $110(20.2)$ & $1.17(0.38$ to 3.59$)$ & $97(19.6)$ & $0.73(0.21$ to 2.47$)$ & \\
\hline 4 & $109(20.0)$ & $1.73(0.61$ to 4.95$)$ & $102(20.6)$ & $0.88(0.27$ to 2.86$)$ & \\
\hline 5 & $109(20.0)$ & $1.18(0.38$ to 3.63$)$ & $104(21.0)$ & $0.51(0.14$ to 1.81$)$ & \\
\hline
\end{tabular}

The flattened relationships require explanation. First is the possibility that a "high allergen home" is also a "dirty home" and that the apparently protective effects exerted by the highest quintiles of allergen exposure in reality reflect protection through correlated high exposures to, perhaps, microbes or their products. This is an explanation that we can neither exclude nor directly study further since our exposure measurements were confined to those of domestic allergens. However, we found no positive correlations between allergen concentration and total weight of dust collected. Family size was related to allergen concentrations of both $\operatorname{Der} p \mathrm{l}$ and $\mathrm{Fel}$ $d \mathrm{l}$ but in opposite directions, and statistical adjustment for sibship did not materially affect the exposure-response relationships. An alternative explanation is immunological and posits that very high allergen exposures exert a "tolerising" effect on sensitisation. The mechanisms for such an effect, if it exists, are speculative. Platts Mills and colleagues, observing in cross section a similar pattern to ours, suggest that high exposure (to $\mathrm{Fel} d \mathrm{l}$ ) may produce a form of tolerance characterised by a "modified" Th2 response with specific $\operatorname{IgG}_{4}$ production. ${ }^{6}$

This is, to our knowledge, the first prospective report of the role of domestic allergen exposures in a representative community sample. The small number of previous descriptions has involved, in part at least, children considered to be at special risk of developing allergy, generally as a method of increasing the frequency of positive outcomes and thus statistical power. We elected not to do this but, rather, to study a population whose experience would be widely generalisable. Our findings are different from those of the other large prospective study of this subject which involved
648 children recruited at birth in five German cities. Positive but monotonic relationships between early exposures to $\operatorname{Der} p$ $\mathrm{l}$ and $\mathrm{Fel} d \mathrm{l}$ and specific sensitisation were found, but there were no associations with wheeze. We suggest that this may reflect in part the much lower allergen exposures in that population. There the median Der $p$ l concentration at 6 months was $0.184 \mu \mathrm{g} / \mathrm{g}$ dust and that of $\mathrm{Fel} d \mathrm{l}$ just $0.055 \mu \mathrm{g} / \mathrm{g}$ dust, respectively about 10 and 50 times lower than the geometric means in Ashford. We attempted to model our outcome data using the four exposure categories reported from the German study. ${ }^{3}$ Although we found broadly the same patterns described above, the exercise was essentially fruitless since $84 \%$ of our cohort exposures fell within the two highest German quartiles of Der $p 1$ and $90 \%$ within the highest quartile of Fel $d \mathrm{l}$. As a result, we may have captured a more extensive picture of the true exposureresponse relationship.

Far closer to the exposures in Ashford were those reported from the United States. ${ }^{6}$ Applying the latter to our outcome data, we again found the same pattern for both allergens with a steep increase at low levels of exposure and attenuated rates at high levels of exposure.

The stratified results suggest that children with an inherited tendency to allergic disease, and those who are born first in a sibship, have a particular immune response to inhaled allergens and that, in other children, the role of early allergen exposure is less relevant. Both factors have consistently been reported to be among the most important determinants of allergic disease and others have shown interactions between the first (parental history) and environmental exposures. ${ }^{314}$ As far as we are aware, this is the 
first time that an interaction between allergen exposure and birth order has been reported. Again ${ }^{15}$ we suggest that the intriguing effects of birth order on allergic disease in childhood warrant further study.

Our findings in a representative cohort of children in southern England studied from birth to the age of 5 years suggest that the relationships of atopy and associated wheeze with allergen exposure are complex. A steep increase in risk occurs at low levels of exposure to both $\operatorname{Der} p \mathrm{l}$ and $\mathrm{Fel} d \mathrm{l}$, primarily in first born children and the offspring of allergic parents. If exposure thresholds for sensitisation or asthma exist, then they appear to be exceedingly low. These findings are true for two uncorrelated allergens and are consistent with data from cross sectional studies in the community and longitudinal analysis in an occupational setting. They imply important and previously unrecognised gene-environment interactions in the development of atopy and associated asthma. They also make it improbable that reductions in domestic allergen exposures alone will have a major impact in reducing the incidence of these diseases in childhood; indeed, measures that reduce rather than eliminate exposure may even give rise to an increase in rates of sensitisation.

\section{ACKNOWLEDGEMENTS}

The authors thank the families and their general practitioners who have made this study possible.

\section{Authors' affiliations \\ P Cullinan, S J MacNeill, J M Harris, S Moffat, C White, P Mills,}

A J Newman Taylor, Department of Occupational and Environmental Medicine, Imperial College School of Medicine at the National Heart and Lung Institute, London, UK

This study was funded by the Colt Foundation.

PC and ANT devised the study. It was supervised by PC and JH. SM, CW and PM collected all the data which were jointly analysed by SMc and $\mathrm{JH}$. PC and SMc wrote the manuscript. All the authors had access to all the data and all hold responsibility for the decision to submit this manuscript.

\section{REFERENCES}

1 Pearce N, Douwes J, Beasley R. Is allergen exposure the major primary cause of asthma? Thorax 2000;55:424-31.

2 Sporik R, Holgate ST, Platts-Mills TA, et al. Exposure to house-dust mite allergen (Der p I) and the development of asthma in childhood. A prospective study. N Engl J Med 1990;323:502-7.

3 Wahn U, Lau S, Bergmann R, et al. Indoor allergen exposure is a risk factor for sensitization during the first three years of life. J Allergy Clin Immunol 1997;99:763-9.

4 Lau S, Illi S, Sommerfeld C, Niggemann B, et al. Early exposure to house-dust mite and cat allergens and development of childhood asthma: a cohort study. Multicentre Allergy Study Group. Lancet 2000;356:1392-7.

5 Kuehr J, Frischer T, Meinert R, et al. Mite allergen exposure is a risk for the incidence of specific sensitization. J Allergy Clin Immunol 1994;94:44-52.

6 Platts-Mills T, Vaughan J, Squillace S, et al. Sensitisation, asthma, and a modified Th2 response in children exposed to cat allergen: a populationbased cross-sectional study. Lancet 2001;357:752-6.

7 Atkinson W, Harris J, Mills P, et al. Domestic aeroallergen exposures among infants in an English town. Eur Respir J 1999;13:583-9.

8 Checkoway H, Pearce N, Crawford-Brown D, eds. Research methods in occupational epidemiology. New York: Oxford University Press, 1989:244-5.

9 Cullinan P, Cook A, Gordon S, et al. Allergen exposure, atopy and smoking as determinants of allergy to rats in a cohort of laboratory employees. Eur Respir J 1999;13:1139-43.

10 Stayner L, Steenland K, Dosemeci M, et al. Attenuation of exposure-response curves in occupational cohort studies at high exposure levels. Scand J Work Environ Health 2003;29:317-24.

11 Heinrich J, Holscher B, Douwes J, et al. Reproducibility of allergen, endotoxin and fungi measurements in the indoor environment. $J$ Expos Anal Environ Epidemiol 2003;13:152-60.

12 Kalra S, Crank P, Hepworth J, et al. Absence of seasonal variation in concentrations of the house dust mite allergen Der $p 1$ in south Manchester homes. Thorax 1992;47:928-31.

13 Kuehr J, Frischer T, Karmaus W, et al. Natural variation in mite antigen density in house dust and relationship to residential factors. Clin Exp Allergy 1994; 24:229-37.

14 Svanes C, Jarvis D, Chinn S, et al. Childhood environment and adult atopy: results from the European Community Respiratory Health Survey. J Allergy Clin Immunol 1999;103:415-20.

15 Sunyer J, Anto JM, Harris J, et al. Maternal atopy and parity. Clin Exp Allergy 2001;31:1352-5. 